\title{
COST-EFFECTIVENESS ANALYSIS OF COUNSELING IN THERAPY FOR OUTPATIENTS WITH HYPERTENSION
}

\author{
DIAH RAMADHANI, URIP HARAHAP, AZIZAH NASUTION*
}

Department of Pharmacology, Faculty of Pharmacy, Universitas Sumatera Utara, Medan, Indonesia. Email: nasution.azizah4@gmail.com

Received:07 March 2018, Revised and Accepted: 25 March 2018

ABSTRACT

Objectives: To determine the effect of counseling on effectiveness and cost of the treatment for outpatient with primary hypertension (HTN) in Cut Meutia Hospital, Indonesia.

Methods: This 6-month prospective quasi-experimental study was undertaken to analyze the impact of counseling toward cost and effectiveness in the treatment in patients with primary HTN and evaluation of each month at Cut Meutia Hospital, Indonesia. The study sample consisted of 22 patients for each group. A cost analysis was conducted from the perspective of the health-care providers. The cost in the treatment of both groups was analyzed by calculating the cost-effectiveness ratio (CER) and incremental CER (ICER).

Results: Most of the patients with HTN (54.55\%) were males with ages ranging from 35 to 64 years old (77.27\%). Patients who achieved a blood pressure < $140 / 90 \mathrm{mmHg}$ on HTN treatment: With counseling, 77.27\%; without counseling, 18.18\%. CER for HTN treatment with and without counseling were Rp 1,756,117,86 and Rp 6,704,247,91, respectively. The ICER was Rp 233,745.13.

Conclusion: Treatment of HTN with counseling was more cost-effective than without counseling.

Keywords: Hypertension, Pharmaceutical care, Counseling, Cost-effectiveness analysis.

(C) 2018 The Authors. Published by Innovare Academic Sciences Pvt Ltd. This is an open access article under the CC BY license (http://creativecommons. org/licenses/by/4. 0/) DOI: http://dx.doi.org/10.22159/ajpcr.2018.v11s1.26555

\section{INTRODUCTION}

High blood pressure (BP) is the most common chronic medical problem and remains as a global public-health challenge [1]. Hypertension (HTN) is a public health concern due to its magnitude, risks, difficulty in management, high medical and social costs, and severe cardiovascular and renal complications [2]. Many studies have reported a significant relationship between HTN and risk factors such as age, body mass index, smoking, and physical inactivity [3].

The prevalence of HTN was estimated to reach $26.4 \%$ of the world's population [1] and has resulted in death of about 7.1 million people per year in the world [4]. According to the World Health Organization estimates, there were $11 \%$ of HTN patients not detected and half of whom were in developing countries, including Indonesia and only $34 \%$ of HTN patients who received comprehensive treatment achieved the target BP [5].

It is predicted that the prevalence of HTN patients will reach $60 \%$ in the year 2025. The increase proportion of the aging population, which subsequently the treatment cost of chronic diseases including HTN and an increase in serious economic burden, an increase in the cost of therapy is also caused by the increasing use of drugs, the new drugs that are more expensive, and the changing patterns of treatment [6].

Uncontrolled BP can lead to various complications such as stroke, heart failure, myocardial infarction, and peripheral vascular disease. Increased BP is the cause of $62 \%$ of cases of cerebrovascular disease, $49 \%$ of ischemic heart disease, and $49 \%$ of heart failure [7,8]. To prevent the occurrence of complications in patients with HTN, the effective pharmacological and non-pharmacological approaches are required to have the patient's BP lie within the target value [9]. Therefore, to achieve qualified and cost-effective health care, the policy of health care should consider the pharmacoeconomics evaluation.

This study can be used as a consideration for policymakers to determine the choice of treatment alternatives to imprected efficiency and effectiveness [10]. Hence, cost-effectiveness analysis (CEA), which is one method of the pharmacoeconomics analysis, needs to be done [11].

To light of the above problems, the present study was to determine the effect counseling on effectiveness and cost of the treatment of primary hypertensive patients admitted to Cut Meutia Hospital, Indonesia.

\section{METHODS}

\section{Study design}

This study was a non-equivalent prospective quasi-experimental design. The target population in this study was all patients with primary HTN in polyclinic specialist of the kidney and HTN Cut Meutia hospital in Lhokseumawe period from May to November 2016.

CEA was performed from the perspective of the health-care providers that social insurance administration organization BadanPenyelenggaraJaminanSosial (BPJS). BPJS is a public agency established to implement the social security program. The health insurance prepared through BPJS is in the form health protection for participants to get health-care benefits and protection to meet the basic needs of health care. The final decision in choosing alternative services used in the treatment of HTN in this study is to compare the cost-effectiveness ratio (CER) of each study group.

\section{Inclusion criteria}

Outpatients with HTN in Cut Meutia hospital, Lhokseumawe, period May to November 2016 with BPJS claim were included into this study, and patients aged 18-80 years willing to receive information as well as approval of voluntary participation and written informed consent. Exclusion criteria were patients with a history disease other than HTN, such as diabetes, heart failure and kidney damage, pregnancy, and cognitive dysfunction.

\section{Data collection}

Patients who met the inclusion criteria were 44 patients and divided into a control group or without counseling $(n=22)$ and group with 
counseling $(\mathrm{n}=22)$. The control group received usual treatment including physician consultation, prescription of antihypertensive drugs, and laboratory tests. The hypertensive patients in the treatment group received usual treatment as well as counseling done monthly by pharmacists for 6 months. Additional counseling by pharmacists includes providing appropriate treatment referrals, information on the side effects of medication, diet, and lifestyle modification. Measurement of BP was performed every patient's visit to the hospital.

\section{Data analysis}

\section{Characteristics of the hypertensive patients}

The characteristics of patients analyzed in this study were the proportion by age, sex, and education. Data were statistically analyzed using Chi-square test.

\section{CEA}

\section{Resources}

CEA was conducted on the basis of health-care payer perspective that is BPJS, so the cost included in the analysis were only direct medical costs. Direct medical costs include physician incentive, the cost of antihypertensive drugs, symptomatic therapy fees, and pharmacist incentive (for the treatment group). The cost of each item was calculated by multiplying the unit cost by the number of units consumed by each group. Then, all the costs of the resources used in each group were added up as shown in Table 1.

Table 1: Categories of resources used in the treatment of patients with primary HTN

\begin{tabular}{|c|c|}
\hline Cost & Unit cost (Rp) \\
\hline Physician incentives & 60.000 \\
\hline Pharmacist incentives & 20.000 \\
\hline \multicolumn{2}{|l|}{ Antihypertensive drug's cost } \\
\hline Amlodipine & 352 \\
\hline Valsartan (Diovan ${ }^{\circledR}$ ) & 3,510 \\
\hline Telmisartan (Micardis ${ }^{\circledR}$ ) & 3,900 \\
\hline Furosemide & 84 \\
\hline Hydrochlorothiazide & 163 \\
\hline Bisoprolol (Concor ${ }^{\circledR}$ ) & 746 \\
\hline \multicolumn{2}{|c|}{ Symptomatic therapy drug's cost: } \\
\hline Simvastatin & 177 \\
\hline Meloxicam & 150 \\
\hline Allopurinol & 232 \\
\hline Lansoprazole & 341 \\
\hline Domperidone & 174 \\
\hline Paracetamol & 88 \\
\hline Mefenamic acid & 127 \\
\hline Scopamin $^{\circledR}$ & 1,100 \\
\hline Epsonal $^{\circledR}$ & 3,300 \\
\hline Neurodex ${ }^{\circledR}$ & 737 \\
\hline Vestein $^{\circledR}$ & 3,500 \\
\hline Alprazolam & 185 \\
\hline
\end{tabular}

\section{Effectiveness}

The measure of the treatment effectiveness used in this study was the percent of patients who achieved a BP of <140/90 mmHg on HTN treatment in both groups. Data were statistically analyzed using Chisquare test.

Cost-effectiveness analysis was performed by determining the costeffectiveness ratio (CER) and the incremental CER (ICER) of each group. CER was the ratio of total direct medical costs by the mean reduction in systolic BP (SBP) and diastolic BP (DBP). ICER treatment of patients with primary HTN calculated using the formula:

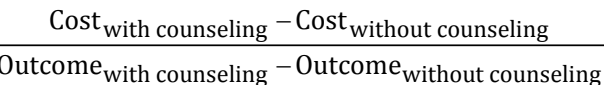

\section{Sensitivity analysis}

This study used a one-way sensitivity analysis that performed to improve the quality and usefulness of the CEA. Drug costs increased to $5 \%, 10 \%$, and $15 \%$. Total direct medical costs, CER, and ICER were recalculated.

All calculations and result plotting were performed using Microsoft Excel 2010 and all statistical analyses were performed using SPSS for Windows version 22 .

\section{RESULTS}

\section{Characteristics of the patients}

Characteristics of the patients in this study in terms of gender, age, and education level are shown in Table 2. Based on the results of statistical analysis, there was no significant difference between male and female patients in the groups with and without counseling $(\mathrm{p}=1.000)$. With regard to age, there was no significant differences between the age groups 35 and 64 years and $\geq 65$ years in the groups with and without counseling ( $p=0.472)$. The same result was also proved that there was no significant difference in levels of education between groups with and without counseling $(\mathrm{p}=0.960)$.

\section{Cost-effectiveness analysis}

Analysis of cost-effectiveness in the treatment of patients with primary HTN could be seen in Table 3 . The direct medical costs of primary HTN treatment per 100 patients in the group without counseling was Rp 121,883,227.00 with BP <140/90 mmHg per 100 patients treated $18.18 \%$, while the direct medical costs of primary HTN treatment per 100 patients in the group with counseling was $\mathrm{Rp} 135,695,227.00$ with $\mathrm{BP}<140 / 90 \mathrm{mmHg}$ per 100 patients treated $77.27 \%$.

The cost of HTN treatment per patient without counseling group was Rp 6,704,247.91; counseling group was $\operatorname{Rp~1,756,117.86.~Based~on~the~}$ analysis of ICER, additional costs required to increase the patient who achieved a BP $<140 / 90 \mathrm{mmHg} 18.18 \%$ to $77.27 \%$ was $\mathrm{Rp} 233,745.13$

Table 2: Characteristics of patients with primary HTN

\begin{tabular}{|c|c|c|c|}
\hline Characteristics & Without counseling $n(n=22 ; \%)$ & With counseling $n(n=22 ; \%)$ & $\mathbf{p}$ \\
\hline Sex & & & 1.000 \\
\hline Male & $12(54.55)$ & $12(54.55)$ & \\
\hline Female & $10(45.45)$ & $10(45.45)$ & \\
\hline Group age (years) & & & 0.472 \\
\hline $35-64$ & $16(72.73)$ & $18(81.82)$ & \\
\hline$\geq 65$ & $6(27.27)$ & $4(18.18)$ & \\
\hline Level of education & & & 0.960 \\
\hline Elementary school & $5(22.73)$ & $6(27.27)$ & \\
\hline Junior high school & $2(9.09)$ & $2(9.09)$ & \\
\hline Senior high school & 7 (31.82) & $5(22.73)$ & \\
\hline Diploma & $2(9.09)$ & $3(13.64)$ & \\
\hline Bachelor & $6(27.27)$ & $6(27.27)$ & \\
\hline
\end{tabular}

HTN: Hypertension 
Sensitivity analysis

The results of the sensitivity analysis are presented in Table 4 . This indicates that the increase in cost of drugs by $5 \%, 10 \%$, and $15 \%$, did not change the conclusions of this study. In other words, if there are changes the value of the inflation of the price of drugs, the costeffectiveness of interventions in this study, counseling, will not change.

\section{DISCUSSION}

Clinical decision-making in the treatment of HTN does not only consider the safety and quality of intervention but should also consider the economic value. This means that the treatment provided must be cost-effective and more affordable by the public and effective to acquire a good clinical outcome [12].

Based on this study, counseling was proven to increase the effectiveness of treatment by lowering in SBP and DBP patients with primary HTN, also could reduce the cost of the use of antihypertensive medications. Patients who received counseling by pharmacists had higher decreased of BP and achieved a BP $<140 / 90 \mathrm{mmHg}$

Based on the analysis of ICER, an additional cost was required to improve treatment outcomes in patients with HTN. Results of the pharmacoeconomics analysis could be used by policymakers (in this case BPJS as health insurance) as one of the considerations to improve the quality of health services in outpatient with primary HTN in Indonesia.

Incremental CER in the treatment of HTN per patient was Rp $233,745.13$. This value was smaller than the gross domestic product per capita Indonesia in 2015 which is Rp 44,568,953.00. Hence, it could be concluded that the treatment of hypertension with counseling was more cost effective compared to those without counseling.

The results of the sensitivity analysis showed that changes in the value of inflation of drug prices will not change the cost-effectiveness of interventions. Thus, it could be concluded that the treatment of HTN with counseling was more cost-effective than without counseling. This was in line with other studies that have proved that effective counseling improves adherence and lower BP to achieve the BP target [13-15]. The research conducted by Sitepu showed a decrease of SBP $24 \mathrm{mmHg}$, $\mathrm{p}=0.000$; DBP $15 \mathrm{mmHg}, \mathrm{p}=0.010$; and the number of patients achieved the target BP $<140 \mathrm{mmHg} 70 \%$ [13]. Another study was conducted by comparing the effect of counseling with poster installation, it was concluded that there was significant difference of SBP and DBP reduction between counseling and poster installation, $p=0.010 ; p=0.018$ [14]. The study of 50 HTN patients at the M. Djamil Hospital, Padang, Indonesia, showed a difference of between SBP before and after counseling of $12.6 \mathrm{mmHg}$ [15]. A more recent study conducted in four primary health centers also confirmed that counseling improved BP of patients with HTN [16]. There was limited study cost-effectiveness study conducted on the management of patients with HTN. However, few economic studies have been undertaken on the management of patients with other diseases. A study was conducted to evaluate the impacts of clinical pharmacy education (CPI) on outcome and costs in the management of infection among patients with chronic kidney disease Stages 4 and 5 in Haji Adam Malik Hospital, Indonesia. It was found that management of the patients with CPI was more cost-effective compared to those without CPI [17]

Some limitations of this study were the relatively small sample size, short duration of counseling session, and short period of study. Factors caused by complications of HTN and comorbidity were not taken into account in this study. These factors may affect morbidity of the patients; therefore, it needs to be considered for the future study.

\section{CONCLUSION}

Counseling improves efficiency and effectiveness in the treatment of primary HTN. Therefore, the participation of the pharmacists in the treatment of HTN was essential to optimize the therapy. The results of this study could be taken into consideration by health policymakers.

Table 3: CEA in the treatment of patients with primary HTN

\begin{tabular}{|c|c|c|}
\hline Items consumed & Costs without counseling (in $R p)(n=22)$ & Cost with counseling (in $R p)(n=22)$ \\
\hline Physician incentives & $9,240,000.00$ & $9,240,000.00$ \\
\hline Pharmacist incentives & - & $3,080,000.00$ \\
\hline Antihypertensive drug's cost & $17,145,540.00$ & $16,967,130.00$ \\
\hline Symptomatic therapy drug's cost & $428,770.00$ & $565,820.00$ \\
\hline Direct medical cost & $26,814,310.00$ & $29,852,950.00$ \\
\hline Cost to treat 100 patients $(\mathrm{x})$ & $121,883,227.00\left(x_{1}\right)$ & $135,695,227.00\left(\mathrm{x}_{2}\right)$ \\
\hline $\begin{array}{l}\text { Outcome (hypothetical } \mathrm{BP}<140 / 90 \mathrm{mmHg} \text { per } \\
100 \text { patients treated) (y) }\end{array}$ & $18.18\left(\mathrm{y}_{1}\right)$ & $77.27\left(y_{2}\right)$ \\
\hline $\begin{array}{l}\operatorname{CER}(\mathrm{x} / \mathrm{y}) \\
\mathrm{ICER}\end{array}$ & Rp 6,704,247.91/patient & Rp 1,756,117.86/patient \\
\hline
\end{tabular}

$\left(\right.$ Cost $\mathrm{x}_{2}-$ Cost $\left.\mathrm{x}_{1}\right) /\left(\right.$ outcome $\mathrm{y}_{2}-$ outcome $\left.\mathrm{y}_{1}\right)=13,812,000.00 / 59.09=233,745.13$

HTN: Hypertension, CEA: Cost-effectiveness analysis, ICER: Incremental cost-effectiveness ratio, CER: Cost-effectiveness ratio, BP: Blood pressure

Table 4: The results of the sensitivity analysis

\begin{tabular}{|c|c|c|}
\hline Description & Without counseling $(n=22)$ & With counseling $(n=22)$ \\
\hline \multicolumn{3}{|l|}{ Direct cost to treat 100 patients $(\mathrm{x})$ at increased: } \\
\hline $5 \%$ of drugs cost & Rp 125,877,389.00 & Rp 139,679,988.00 \\
\hline $10 \%$ of drugs cost & $\operatorname{Rp} 129,871,549.00$ & Rp $143,664,750.00$ \\
\hline $15 \%$ of drugs cost & Rp 133,865,711.00 & Rp 147,649,511.00 \\
\hline Outcome (BP $<140 / 90 \mathrm{mmHg}$ per 100 patients treated) (y) & $18.18\left(y_{1}\right)$ & $77.27\left(\mathrm{y}_{2}\right)$ \\
\hline \multicolumn{3}{|l|}{ CER $(\mathrm{x} / \mathrm{y})$ in Rp/patient at increased: } \\
\hline $5 \%$ of drugs cost & $6,923,948.79$ & $1,807,687.18$ \\
\hline $10 \%$ of drugs cost & $7,143,649.56$ & $1,859,256.50$ \\
\hline $15 \%$ of drugs cost & $7,363,350.44$ & $1,910,825.82$ \\
\hline ICER at increased: & $\mathrm{Rp} /$ patient & \\
\hline $5 \%$ of drugs cost & $233,586.04$ & \\
\hline $10 \%$ of drugs cost & $233,426.99$ & \\
\hline $15 \%$ of drugs cost & $233,267.90$ & \\
\hline
\end{tabular}

BP: Blood Pressure, CER: Cost-effectiveness ratio; ICER: Incremental cost-effectiveness ratio 


\section{COMPETING INTEREST}

The authors have no conflict of interest to report.

\section{REFERENCES}

1. Kearney PM, Whelton M, Reynolds K, Muntner P, Whelton PK, He J. Global burden of hypertension: Analysis of worldwide data. Lancet 2005;365:217-23.

2. Chobanian AV, Bakris GL, Black HR, Cushman WC, Green LA, Izzo JL Jr., et al. The seventh report of the joint national committee on prevention, detection, evaluation, and treatment of high blood pressure: The JNC 7 report. JAMA 2003;289:2560-72.

3. Booth FW, Gordon SE, Carlson CJ, Hamilton MT. Waging war on modern chronic diseases: Primary prevention through exercise biology. J Appl Physiol 2000;88:774-87.

4. Chobanian AV. The seventh report of the joint national committee on prevention, detection, evaluation and treatment of high blood pressure. The JNC 7 report. JAMA 2003;2560-72.

5. Markovic BB. Treatment of hypertension by general practioners and hypetensive drugs expenditure in an urban environment. Coll Antropol 2009;33:71-6.

6. Bootman JL, Townsend RJ, McGhan WF. Principles of Pharmacoeconomics. $3^{\text {rd }}$ ed. Cincinnati: Harvey White Books Company; 2005. p. 8-9.

7. Lawes CM, Hoorn SV, Rodgers A. Global burden of blood-pressurerelated disease. Lancet 2008;371:1513-8.

8. Lawes CM, Hoorn SV, Law M, Elliott P. High blood pressure. In: Ezzati M, Lopez A, Rodgers A, Hoorn SV, Murray C, editors. Comparative Quantification of Health Risks: Global and Regional Burden of Disease due to Selected Major Risk Factors. Geneva: World
Health Organization; 2004. p. 281-390.

9. Wu Y, Quan Z, Jianwei X, Meng L, Susan Z, Yushi H, et al. A cost effectiveness analysis between amlodipine and angiotensin II receptor blockers in stroke and myocardial infarction prevention among hypertension patients in china. Value Health Reg Issues 2013;2:75-80.

10. Drummond MF, O'Brien BJ, Stoddart GL, Torrance GW. Methods for the Economic Evaluation of Health Care Programmes. $2^{\text {nd }}$ ed. New York: Oxford University Press, Inc.; 1997. p. 8-9.

11. Arnold RJ. Pharmacoeconomics: From Theory to Practice. Florida: CRC Press; 2010. p. 96.

12. Rustiani E, Retnosari A, Arsyanti L. Analysis of usage antihypertensive drugs in outpatient polyclinic PMI hospital Bogor: A comparison of cost effectiveness and patients' quality of life. Indonesian J Pham Sci 2014;12:209-15.

13. Sitepu NB, Harahap U, Nasution SR. Evaluation of pharmaceutical care towards therapeutic outcomes and the primary hypertensive patients' quality of life in a hospital. Indonesian J Pharm 2014;7:42-9.

14. Putri RA, Andrajati R, Bahtiar A. Analysis of the effectiveness of counseling and poster towards adherence and therapeutic outcome on hypertensive patients. J Manag Pharm Pract 2013;3:117-24.

15. Pratiwi D. Impact of Drug Counseling on Adherence of Hypertensive Patients in Special Polyclinic Dr. M. Djamil Padang Hospital. Thesis, Universitas Andalas; 2011.

16. Nasution A, Tanjung HR. Impacts of counseling on adherence to prescribed medications and blood pressure of hypertensive patients in four Indonesian primary health centers. Int $\mathrm{J}$ Pharm Pharm Sci 2015;7:114-7.

17. Nasution A, Sulaiman SS, Shafie AA. Cost-effectiveness of clinical pharmacy education on infection management among patients with chronic kidney disease in an Indonesian hospital. Value Health Reg Issues 2013;2:43-7. 